\title{
Examining the Role of the Human Hippocampus in Approach-Avoidance Decision Making Using a Novel Conflict Paradigm and Multivariate Functional Magnetic Resonance Imaging
}

\author{
๑DEdward B. 0’Neil, ${ }^{1 \star}$ Rachel N. Newsome, ${ }^{1 \star}$ Iris H.N. Li, ${ }^{1 \star ~}$ @S Sathesan Thavabalasingam, ${ }^{1}$ @Rutsuko Ito, ${ }^{1,2}$ \\ and ${ }^{(D A n d y}$ C.H. Lee ${ }^{1,3}$ \\ ${ }^{1}$ Department of Psychology (St. George and Scarborough), University of Toronto, Toronto M5S 3G3/M1C 1A4, Canada, ${ }^{2}$ Department of Cell and Systems \\ Biology, University of Toronto, Toronto M5S 3G5, Canada, and ${ }^{3}$ Rotman Research Institute, Baycrest Centre for Geriatric Care, Toronto M6A 2E1, Canada
}

Rodent models of anxiety have implicated the ventral hippocampus in approach-avoidance conflict processing. Few studies have, however, examined whether the human hippocampus plays a similar role. We developed a novel decision-making paradigm to examine neural activity when participants made approach/avoidance decisions under conditions of high or absent approach-avoidance conflict. Critically, our task required participants to learn the associated reward/punishment values of previously neutral stimuli and controlled for mnemonic and spatial processing demands, both important issues given approach-avoidance behavior in humans is less tied to predation and foraging compared to rodents. Participants played a points-based game where they first attempted to maximize their score by determining which of a series of previously neutral image pairs should be approached or avoided. During functional magnetic resonance imaging, participants were then presented with novel pairings of these images. These pairings consisted of images of congruent or opposing learned valences, the latter creating conditions of high approach-avoidance conflict. A data-driven partial least squares multivariate analysis revealed two reliable patterns of activity, each revealing differential activity in the anterior hippocampus, the homolog of the rodent ventral hippocampus. The first was associated with greater hippocampal involvement during trials with high as opposed to no approach-avoidance conflict, regardless of approach or avoidance behavior. The second pattern encompassed greater hippocampal activity in a more anterior aspect during approach compared to avoid responses, for conflict and no-conflict conditions. Multivoxel pattern classification analyses yielded converging findings, underlining a role of the anterior hippocampus in approachavoidance conflict decision making.

Key words: approach-avoidance conflict; decision making; functional magnetic resonance imaging; hippocampus; memory

Significance Statement

Approach-avoidance conflict has been linked to anxiety and occurs when a stimulus or situation is associated with reward and punishment. Although rodent work has implicated the hippocampus in approach-avoidance conflict processing, there is limited data on whether this role applies to learned, as opposed to innate, incentive values, and whether the human hippocampus plays a similar role. Using functional neuroimaging with a novel decision-making task that controlled for perceptual and mnemonic processing, we found that the human hippocampus was significantly active when approach-avoidance conflict was present for stimuli with learned incentive values. These findings demonstrate a role for the human hippocampus in approach-avoidance decision making that cannot be explained easily by hippocampal-dependent long-term memory or spatial cognition.

\section{Introduction}

There has been increasing interest in a potential role for the hippocampus (HC) in decision making, which goes beyond a puta- tive role for this structure in long-term declarative memory (Johnson et al., 2007; Wimmer and Shohamy, 2012; Abela et al.,

This work was supported by Natural Sciences and Engineering Research Council of Canada Grants 402642 (R.I.) and 491728 and 491785 (A.C.H.L.) and a Research Competitiveness Award from the University of Toronto Scarborough (R.I., A.C.H.L.). We thank all participants for their time and Anusha Ravichandran for assistance with neuroimaging data collection. 
2013). One suggestion arising primarily from rodent work is that the ventral $\mathrm{HC}$ is important in mediating an animal's response to approach-avoidance conflict (Gray and McNaughton, 2000; Bannerman et al., 2014), a scenario that arises when a stimulus or situation is associated simultaneously with reward and punishment. For example, converging lesion and electrophysiological evidence has revealed ventral $\mathrm{HC}$ involvement in ethological tests of anxiety such as the elevated plus maze, light/dark box, and open field, in which an animal is faced with a decision to explore a potentially dangerous or rewarding environment (Bannerman et al., 2002, 2003; Kjelstrup et al., 2002; McHugh et al., 2004; Trivedi and Coover, 2004; Adhikari et al., 2010, 2011).

Although anatomical connectivity evidence suggests that primate anterior $\mathrm{HC}$ is the homolog of rodent ventral HC (Aggleton, 2012; Strange et al., 2014), there is limited evidence that the human anterior HC plays a similar role in conflict processing (Bach et al., 2014, Oehrn et al., 2015). Intriguingly, one previous study demonstrated that anterior HC activity fluctuated with threat level when participants searched for tokens in a virtual spatial environment in the presence of a sleeping predator (Bach et al., 2014). Specifically, anterior HC activity was significantly greater within a context that was associated with a high, as opposed to low, probability of the predator waking (i.e., high approachavoidance conflict). While these findings hint at parallels between the rodent and human literature, a number of key issues remain unresolved. First, existing work has often relied on unlearned stimuli to elicit approach-avoidance conflict, for example, presenting rats with the choice to explore potentially dangerous open spaces (approach) or stay in innately preferred enclosed spaces (avoidance) in the elevated T-maze task (Bannerman et al., 2003). Similarly, operant models of approach-avoidance conflict such as the Vogel (Vogel et al., 1971) and Geller-Seifter (Geller and Seifter, 1960) tests rely on the simultaneous presentation of unconditioned stimuli (reward/water and shock) to induce conflict and have not, to our knowledge, been explicitly used to assess ventral HC function. It is uncertain, therefore, whether HC involvement in conflict resolution extends to stimuli for which incentive values are learned, an important question given that high-conflict scenarios arise not just from innate incentive values but also those acquired with experience. This is particularly true for humans, for whom situations of approach-avoidance conflict are less likely to be predicated on factors that underpin rodent behavior, such as foraging for food and avoiding dangerous predators, and are more likely to involve stimuli that acquire their incentive values over time. Second, human and certain rodent approach-avoidance conflict paradigms require spatial and/or mnemonic processing (Bach et al., 2014; Bannerman et al., 2014). Since this is difficult to match across conditions of varying conflict, HC involvement in conflict resolution may reflect differences in spatial cognition or memory demands across conditions rather than a role in conflict resolution per se. Finally, if the human HC does indeed contribute to conflict resolution, it is unknown whether this involvement differs between approach and avoidance behavior. For instance, if $\mathrm{HC}$ activity associated with conflicting incentive cues primarily reflects anxiety (McNaughton and Corr, 2004; Bach et al., 2014), then one would

The authors declare no competing financial interests.

*E.B.O., R.N.N., and I.H.N.L. contributed equally to this work.

Correspondence should be addressed to either Andy C.H. Lee or Rutsuko Ito, Psychology, University of Toronto Scarborough, 1265 Military Trail, Toronto, ON M1C 1A4, Canada, E-mail: andych.lee@utoronto.ca or rutsuko.ito@utoronto.ca.

DOI:10.1523/JNEUROSCI.1915-15.2015

Copyright $\odot 2015$ the authors $\quad 0270-6474 / 15 / 3515040-11 \$ 15.00 / 0$ expect greater activity when making the more dangerous decision to approach as compared to avoid an unknown scenario due to the potential threat of punishment.

To investigate these issues, we developed a novel task in which participants first learned to approach or avoid face scene pairs that were arbitrarily associated with the gain or loss of points. During functional magnetic resonance imaging (fMRI), participants then decided whether to approach or avoid novel recombinations of these stimulus pairs, with each pair comprised of images possessing congruent or opposing trained reward contingencies, leading to the absence or presence of approach-avoidance conflict, respectively. HC activity across approach and avoidance responses during conflict and no-conflict trials was examined using data-driven spatiotemporal partial least squares (PLS; McIntosh et al., 2004) and complementary multivoxel pattern classification analyses (MVPA).

\section{Materials and Methods}

Participants. Twenty right-handed University of Toronto graduate students took part in the study. All subjects were neurologically healthy and did not report a history of mental illness. Data from two individuals were excluded from analyses due to a software failure in recording behavioral responses during MRI scanning. The remaining 18 participants (nine female) were 21-29 years old (mean, 25.25 years; SD, 2.32) with normal or corrected vision. All subjects gave informed written consent before participation and received monetary compensation (CAD 50) for their time. This study was approved by the University of Toronto (Ref. 27455) and Centre for Addiction and Mental Health (CAMH; Ref. 096/2012) research ethics boards.

Behavioral paradigm. We designed a novel task inspired by a previous rodent paradigm of approach-avoidance conflict decision making (Nguyen et al., 2015; Schumacher et al., 2015). Participants played a computerized game comprised of three phases ("learning," "refresher," and "decision"), in which the instructed goal in each phase was to earn as many points as possible. In the initial learning phase, conducted on a 15.2 inch laptop computer outside the scanner, participants learned to approach or avoid a series of color image pairs that were associated with reward or punishment (Fig. 1A). Each pair comprised a face and scene image (both $250 \times 250$ pixels) presented side by side. The face images were courtesy of M. J. Tarr (Center for the Neural Basis of Cognition and Department of Psychology, Carnegie Mellon University, Pittsburgh; http://wiki.cnbc.cmu.edu/Face_Place; NSF Award 0339122; Righi et al., 2012), and the scenes were taken from the MIT Massive Memory database (http://cvcl.mit.edu/mm/stimuli.html; Konkle et al., 2010). Our use of two stimulus categories was motivated by two reasons. First, a body of work has implicated the HC in processing between-domain (e.g., facescene) associations, with cortex surrounding the HC (i.e., perirhinal cortex) being able to support within-domain associations (Mayes et al., 2007). Second, using pairings from a single category (e.g., scene images) could lead to an increased sense of familiarity, and potentially confusability, within and across the different phases of the task. We sought to reduce this by creating pairings from two image categories, thereby increasing the distinctiveness of all image pairs. For each image pair, participants used prespecified, highlighted keys on the laptop to signal approach (" 1 " key) or avoidance ("9" key). Approaching or avoiding a pair associated with positive valence led to a gain of 100 or 0 points, respectively, whereas approaching or avoiding a pair associated with negative valence resulted in a loss of 100 or 0 points, respectively. There were 12 learning blocks of 66 trials, with a short break after every four blocks. Each block contained the same 60 face-scene pairs presented in a pseudorandomized order, with a total of 30 positive and 30 negative valence pairs comprised of equal, counterbalanced numbers of emotionally neutral male/female faces and indoor/outdoor scenes. Every 10 face-scene pairs, a scrambled baseline trial (used as practice for the scrambled baseline trials in the later scanned decision phase) was presented. In these trials, scrambled images of a face and a scene were paired, and participants were required to detect the presence of a dot on one of these 


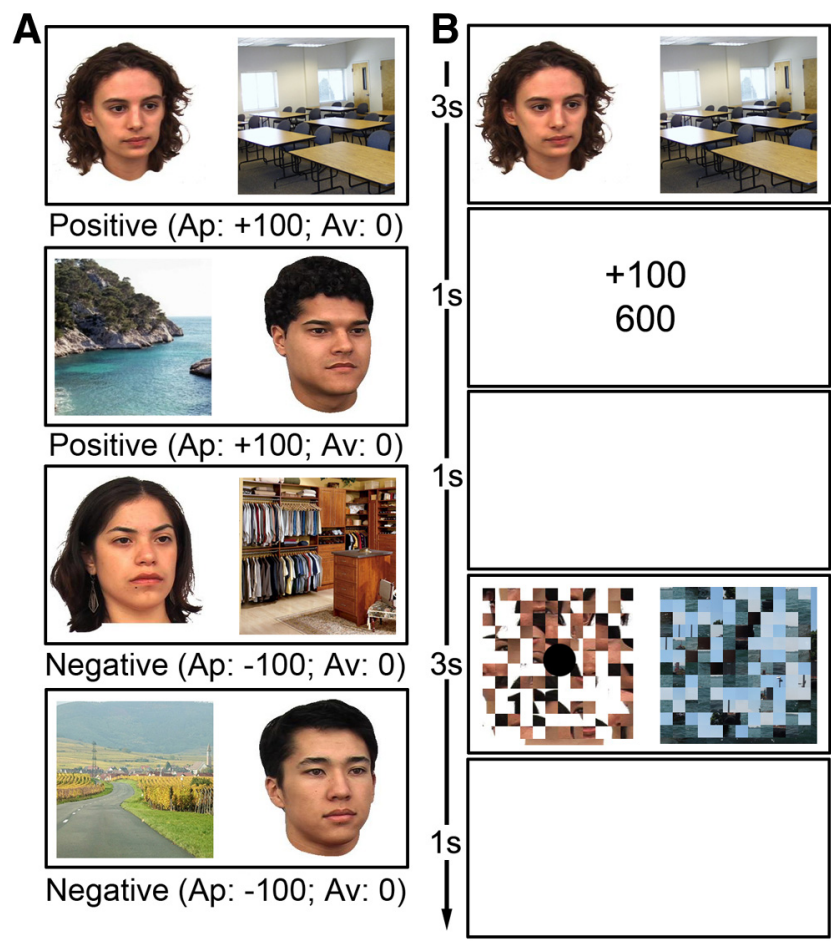

Figure 1. A, Examples of two positive valence and two negative valence face-scene image pairs (total 30 pairs each) along with the number of points gained or deducted following an approach (Ap) or avoid (Av) response. $\boldsymbol{B}$, Schematic representation of the approach/avoidance and scrambled baseline trials. Each face-scene pair was followed by a feedback screen indicating the number of points gained or lost as well as the participant's cumulative score. No feedback was provided for the scrambled baseline trials.

scrambled images. There were four unique scrambled baseline trials repeated six times every four blocks, and the position of the dot was counterbalanced (left/right; scrambled face/scene). All image pairs were presented for $3 \mathrm{~s}$, and the face-scene trials were followed by a $1 \mathrm{~s}$ feedback screen displaying the outcome of the participant's response $(+100,0$, $-100)$ and a cumulative score that was reset to 0 every four blocks. The left/right position of all images was counterbalanced across blocks, and there was an intertrial interval (ITI) of $1 \mathrm{~s}$ (Fig. 1B).

After the 12 learning blocks, participants completed an fMRI scanning session where they first completed a refresher phase fMRI run, followed by three critical decision phase fMRI runs. The refresher task run was designed to prepare participants for the three decision phase runs. The same 30 positive valence and 30 negative valence face-scene pairs from the learning phase were presented in a pseudorandomized order, intermixed with the four previously seen scrambled baseline trials presented five times each (i.e., 20 baseline trials in total). Similar to the learning phase, all image pairs were displayed for $3 \mathrm{~s}$, and the participants were required to make an approach/avoid response for the face-scene pairs or a left/right response for the scrambled images using prespecified buttons on a button box held in the right hand. A $1 \mathrm{~s}$ fixation cross and $1 \mathrm{~s}$ feedback screen followed the face-scene pairs only, and there was a jittered ITI of mean $3.5 \mathrm{~s}$. Notably, since the focus of the current paper is on the role of the $\mathrm{HC}$ during conflict resolution, the neuroimaging data from this phase are not considered here.

Finally, in each decision phase fMRI run, the 60 original face-scene pairs from the learning and refresher phases were recombined and presented as 60 novel pairings: 20 were composed of faces and scenes that were originally part of rewarded pairs (no-conflict positive), 20 of items that were originally part of punished pairs (no-conflict negative), and 20 were pairs that contained one face or scene that was originally rewarded and another face or scene that was originally associated with negative valence (conflict mixed; Fig. $2 A$ ). Thus, there were a total of 60 trials per experimental condition across the three decision phase runs. The participants were not informed of these recombinations and were required to
A
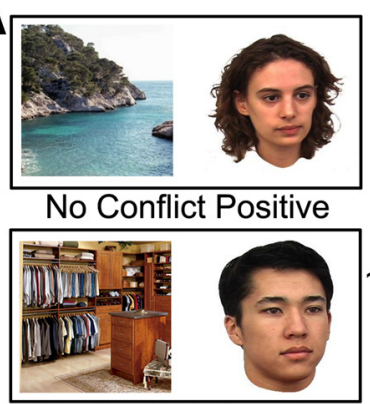

No Conflict Negative

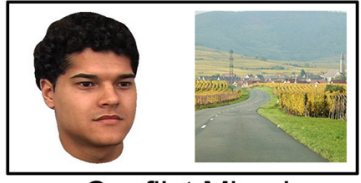

Conflict Mixed

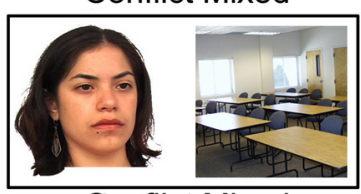

Conflict Mixed

Figure 2. $\quad \boldsymbol{A}$, Examples of the recombined face-scene pairs that were presented during the decision phase ( 20 no-conflict positive, 20 no-conflict negative, and 20 conflict mixed pairs per fMRI run). The presented examples are recombinations of the image pairs shown in Figure $1 A$. No-conflict pairs were comprised of images from the learning phase of the same valence, whereas high-conflict pairs consisted of images from the learning phase of opposing valences. $B$, Schematic representation of the decision and scrambled baseline trials during $\mathrm{fMRI}$ scanning. No feedback was provided during the decision phase.

decide whether to approach or avoid each pair using a button press. In each of the three experimental runs, the 60 face-scene trials were pseudorandomly ordered and intermixed with 20 baseline trials (i.e., scrambled face-scene pairs from the learning phase for which the participants had to indicate the left/right location of a dot with a button press). In all trials, the stimuli were presented for $3 \mathrm{~s}$, with a jittered mean ITI of $3.5 \mathrm{~s}$ and no feedback (Fig. 2B). Run order was varied across subjects.

All phases of the paradigm were programmed and administered using E-Prime version 2.2 (Psychology Software Tools). During the refresher and decision tasks, the stimuli were projected onto a screen situated at the rear opening of the MRI scanner bore, which could be seen via a mirror located on the MRI head coil.

Behavioral data analysis. For all task phases, behavioral performance was assessed according to the proportion of approach responses made and the mean response times. Learning data were examined using two repeated measures ANOVAs (one for each dependent variable) with two within-subject factors of block (1 to 12) and condition (positive vs negative valence). To compare performance on the refresher phase with that of the learning phase, a repeated measures ANOVA with within-subject factors of phase (final learning block vs refresher) and condition (positive vs negative valence) was conducted. Finally, the participants' choices during the decision phase were analyzed with a repeated measures ANOVA with two within-subject factors of run (1 to 3 ) and condition (no-conflict negative vs no-conflict positive vs conflict mixed). An identical repeated measures ANOVA was used to interrogate the response times during the decision phase, except the "condition" factor was comprised of four levels (no-conflict negative avoid, no-conflict positive approach, conflict mixed avoid, conflict mixed approach). The Greenhouse-Geisser correction was applied in instances where sphericity was violated (indicated by adjusted degrees of freedom), and where applicable, significant interactions were explored using post hoc tests Bonferroni corrected for multiple comparisons.

Neuroimaging data acquisition. Neuroimaging data were collected at the MRI Unit of the CAMH Research Imaging Centre (Toronto, Canada) using a 3T Signa MR system (GE Medical Systems). A total of four fMRI 
data series were acquired for each subject (one for the refresher task, comprising 226 volumes, and three for the decision task, each comprising 186 volumes) using a blood oxygenation level-dependent spiral in/ out sequence [Glover, 2012; 47 slices/volume; interslice distance, $0 \mathrm{~mm}$; voxel size, $3.5 \times 3.5 \times 3.5 \mathrm{~mm}$; repetition time $(\mathrm{TR}), 3000 \mathrm{~ms}$; echo time (TE), $30 \mathrm{~ms}$; flip angle (FA), $60^{\circ}$; matrix size, $64 \times 64$ ]. For standard template registration purposes, each participant also received a highresolution $3 \mathrm{D}$ anatomical scan using a T1 BRAVO sequence (200 slices/ volume; voxel size, $0.9 \times 0.9 \times 0.9 \mathrm{~mm}$; TR, $6.7 \mathrm{~mm}$; TE, $3 \mathrm{~ms}$; FA, $8^{\circ}$; matrix size, $256 \times 256$ )

Neuroimaging data preprocessing. Before statistical analyses, each run of functional data for each participant was subjected to a series of preprocessing steps using the FMRI Expert Analysis Tool (FEAT version 5.98) from the FMRIB (Functional MRI of the Brain) software library (FSL; http:/www.fmrib.ox.ac.uk/fsl). These included (1) visual inspection of the data to identify any significant movement or distortion, (2) motion correct using the Motion Correction FMRIB's Linear Registration Tool, (3) brain extraction using the Brain Extraction Tool, (4) grand mean scaling, (5) high-pass temporal filtering with a $50 \mathrm{~s}$ cutoff, (6) spatial smoothing with a Gaussian kernel of $6 \mathrm{~mm}$ full-width at halfmaximum, (7) coregistration to individual anatomical space using boundary-based registration, and (8) normalization to the Montreal Neurological Institute 152 (MNI-152) $2 \mathrm{~mm}$ standard template using the FSL nonlinear registration tool FNIRT. In addition, the first two volumes were discarded from each run for each participant due to signal instability.

Neuroimaging data statistical analysis. Spatiotemporal PLS analysis (McIntosh et al., 2004; Krishnan et al., 2011) was used to explore the covariance between every voxel, across all experimental conditions, at each time point (i.e., at each TR) for the duration of each trial. Since PLS is a multivariate technique and does not make assumptions about the shape of the hemodynamic response function (HRF), it is able to reveal how multivoxel patterns of activity change over time and is more sensitive to small but reliable changes in activity compared to standard univariate statistical analyses that rely on the implementation of a general linear model (GLM) and assumed HRF function (McIntosh and Lobaugh, 2004). We adopted a data-driven, or mean-centered, PLS approach, which effectively allowed us to identify the most salient profiles of neural activity in relation to our experimental conditions without the specification of a priori contrasts. Because we were primarily interested in the difference between no-conflict trials and conflict trials for which the participants had successfully transferred their knowledge from the learning phase, we focused our analyses on no-conflict trials for which the response reflected training as well as conflict trials regardless of response, because inherent in the design of the conflict trials, neither approach nor avoid responses could be considered correct. This resulted in the following conditions: (1) an avoid response was made to a no-conflict negative stimulus pair ("no-conflict negative avoid"), (2) an approach response was made to a no-conflict positive stimulus pair ("no-conflict positive approach"), (3) an avoid response was made to a conflict mixed valence stimulus pair ("conflict mixed avoid"), (4) an approach response was made to a conflict mixed valence stimulus pair ("conflict mixed approach"), and (5) a baseline scrambled image pair was presented ("scrambled baseline"). For each of these trials, a 15 s time window was specified from stimulus onset, i.e., five TRs of $3 \mathrm{~s}$ each. A covariance matrix was calculated between a matrix specifying the different task conditions (design matrix) and a matrix specifying the activity at each voxel, at each time point of the specified time window, for each condition for all subjects (data matrix). This covariance matrix was then submitted to singular value decomposition to extract a number of latent variables (LVs), each comprising a linear contrast between the task conditions and a singular image, which reflects the spatiotemporal pattern of voxels that embody this linear contrast. The LVs were ranked according to the amount of covariance that they accounted for (known as the singular value), and each voxel was associated with a salience or weight that was proportional to this. To determine the statistical significance of each LV, nonparametric permutation testing was used with 500 iterations and a significance threshold of $p<0.05$. This involved randomly reassigning each subject's data without replacement to different experimental con- ditions, calculating a new set of LVs for each new sample, and determining the probability that permuted singular values exceeded the original singular values. Similarly, the reliability of the voxel saliences in each LV was assessed using a bootstrap procedure $(n=100)$. Each bootstrap was created using sampling with replacement, and PLS was recalculated for each sample. For the current study, a bootstrap ratio (BSR; ratio of the salience to bootstrap standard error) of 2.81, corresponding approximately to $p<0.005$, with a cluster threshold of 10 voxels, was considered significant. Notably, corrections for multiple comparisons are not necessary with the PLS approach since permutation tests are conducted on the full spatiotemporal pattern.

Beyond PLS, we were also interested in whether alternative multivariate approaches, in particular MVPA, could shed light on the role of the $\mathrm{HC}$ in approach-avoidance conflict processing. More specifically, although our study was optimized for PLS rather than MVPA approaches (both with respect to paradigm design and fMRI data acquisition parameters), the use of MVPA to conduct a targeted assessment of anterior and posterior HC involvement could, nevertheless, reveal converging findings to our PLS approach. MVPA was performed on per-trial $t$ statistic maps generated using an approach described in the literature (Mumford et al., 2012). Using the preprocessed neuroimaging data from the three decision phase fMRI runs, we calculated a series of per-trial GLMs for each subject with FEAT. Each GLM had a predictor modeling the trial of interest and a predictor of no interest that modeled all other trials for a given run. These predictors, as well as their temporal derivatives, were convolved with a double-gamma HRF function, and a contrast specifying the trial of interest was evaluated. The resulting $t$ statistic maps (one per trial) were concatenated into a single $4 \mathrm{D}$ volume and $z$ transformed, and classification labels were assigned according to the trained valence of the images for a given trial (i.e., positive, negative, or mixed). This approach was favored over classification based upon subject response (i.e., approach vs avoid) because it allowed all trials to be used in the analysis, resulting in a balanced number of training examples for each condition and subject. The Princeton MVPA toolbox (http://code.google.com/p/ princeton-mvpa-toolbox/) and custom Matlab (http://www.mathworks. com) scripts were used for classification. A hold-one-run-back crossvalidation approach was used in conjunction with a linear support vector machine classifier [LIBSVM (Library for Support Vector Machines); http://www.csie.ntu.edu.tw/ cjlin/libsvm/] with a constant cost parameter of $C=1$. Classification was performed separately for each subject on anterior and posterior HC masks. These masks were created using the Harvard-Oxford subcortical structural atlas, thresholded at 50\%. The left and right $\mathrm{HC}$ were each divided into anterior and posterior segments with an equal number of voxels and then combined across hemispheres to create a bilateral anterior (527 voxels) and a bilateral posterior (527 voxels) HC region of interest (ROI). Feature selection was calculated for each participant (excluding the test data) using an omnibus ANOVA thresholded at $p \leq 0.1$. Group classification accuracies were tested against chance performance (50\% for two-way, $33.33 \%$ for three-way classification) using a one-way $t$ statistic.

\section{Results}

\section{Behavioral findings}

The learning phase data revealed that the participants were able to successfully learn to approach the positive valence face-scene pairs and avoid negative valence pairs (Fig. 3A). Participants started off with a general approach strategy in learning block 1 but quickly increased their avoidance responses to image pairs associated with a point penalty from block 2 onward. There were significant factors of condition $\left(F_{(1,17)}=327.44, p<0.0001\right)$ and block $\left(F_{(4.15,70.47)}=37.70, p<0.0001\right)$ as well as a significant interaction between these two factors $\left(F_{(3.91,66.43)}=81.03, p<\right.$ $0.0001)$. Two-tailed pairwise $t$ tests (corrected for multiple comparisons, $p=0.05 / 12=0.0042$ ) revealed that this interaction was driven by a significant difference in the proportion of approach responses between positive and negative valence trials from block 2 to block 12 (all $\left.t_{(17)} \geq 4.86, p<0.0001\right)$, but not in the very first 

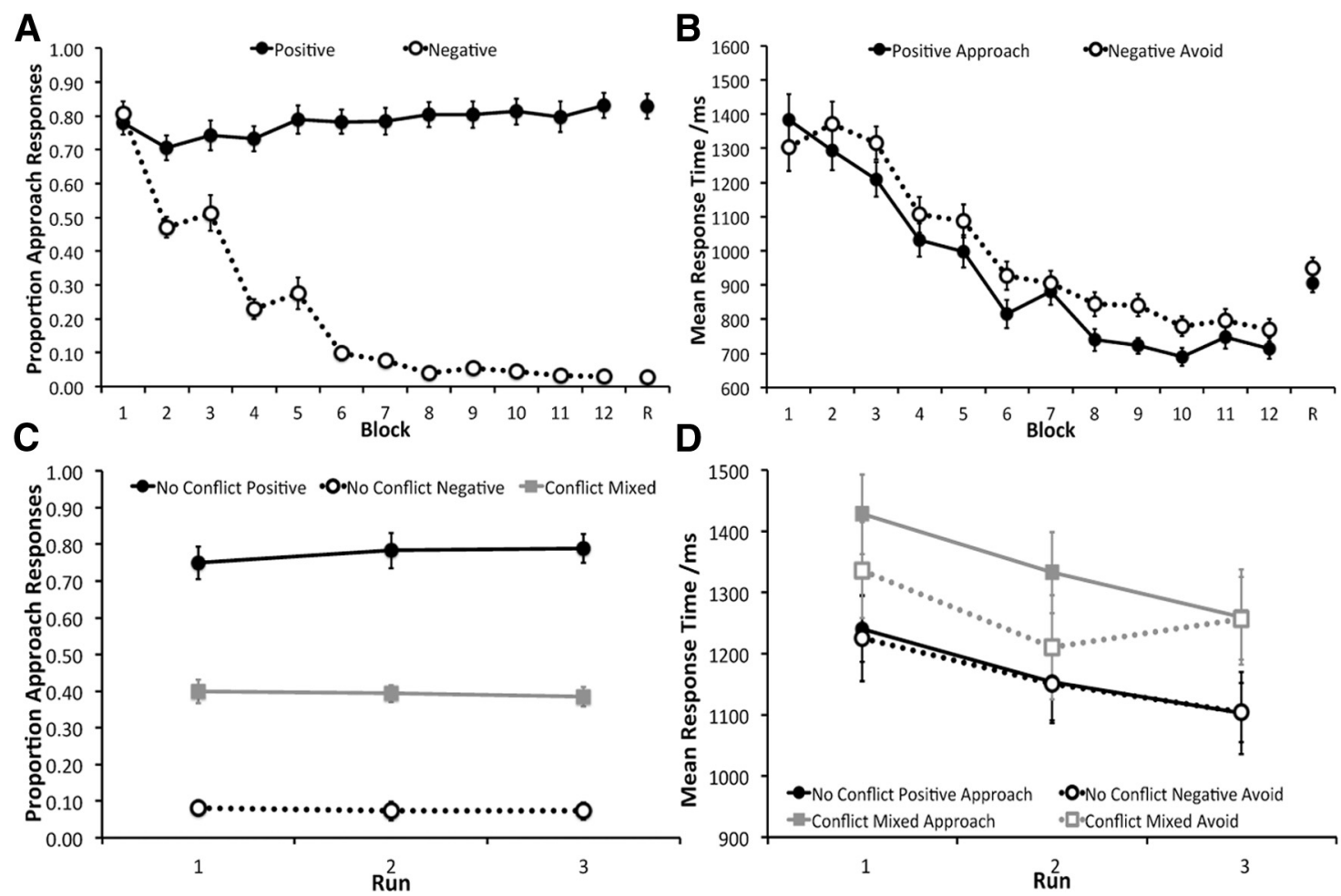

Figure 3. $\quad \boldsymbol{A}, \boldsymbol{B}$, Proportion of approach responses $( \pm \mathrm{SE} ; \boldsymbol{A})$ and mean response times $( \pm \mathrm{SE} ; \boldsymbol{B})$ across the 12 learning phase blocks and the refresher block (R) for the positive and negative valence face-scene pairs. C, Proportion of approach responses ( \pm SE) across the three decision fMRI runs for no-conflict negative valence recombined pairs, no-conflict positive valence recombined pairs, and conflict mixed valence recombined pairs. $\boldsymbol{D}$, Mean response times ( \pm SE) across the three decision $\mathrm{fMRl}$ runs for no-conflict negative valence avoid trials, no-conflict positive valence approach trials, conflict mixed valence avoid trials, and conflict mixed valence approach trials.

block $\left(t_{(17)}=0.70, p=0.49\right)$. Performance at block 12 , as measured by the proportion of the most beneficial response [approach for positive trials and avoid (i.e., one minus proportion approach) for negative trials], was significantly above chance for both trial types (positive, $t_{(17)}=8.73, p<0.0001$; negative, $t_{(17)}=$ $66.56, p<0.0001)$. Participants were significantly better at avoiding negative images pairs compared to approaching positive image pairs $\left(t_{(17)}=3.64, p=0.002\right)$.

Response times also reflected learning across blocks, with a decrease in mean response time for positive and negative valence trials for which the participants made an approach and avoid response, respectively (Fig. $3 B$ ). The factors of condition $\left(F_{(1,17)}=15.77, p=0.001\right)$ and block $\left(F_{(2.49,42.28)}=62.51, p<\right.$ $0.0001)$ were both significant, as was the interaction effect $\left(F_{(3.97,67.48)}=3.38, p=0.014\right)$. The latter reflected no significant differences in response time between positive valence approach and negative valence avoid trials in blocks 1,2 , and 7 (all $t_{(17)} \leq$ $1.57, p>0.13)$, with a trend toward a significant difference in blocks $3,4,5,11$, and 12 (all $t_{(17)}$ between 2.38 and 2.90, $p$ values between 0.01 and 0.03 ) and a significant difference in blocks 6,8 , 9 , and 10 (all $\left.t_{(17)} \geq 4.36, p<0.0001\right)$.

The refresher phase performance demonstrated that despite a change in context from being in a behavioral testing room to lying in the scanner, participants were able to maintain knowledge of the reward/punishment contingencies of the face-scene pairs (Fig. $3 A, B$ ). There was no significant difference in the profile of responses during the refresher phase compared to the final learning block, as reflected in a significant main effect of condition $\left(F_{(1,17)}=455.21, p<0.0001\right)$ but not phase $\left(F_{(1,17)}=0.10, p=0.76\right)$, nor an interaction between the two $\left(F_{(1,17)}=0.01, p=0.93\right)$. Participants were, however, significantly slower to respond during the refresher phase, with a significant main effect of condition $\left(F_{(1,17)}=\right.$ $6.01, p<0.0001)$ and phase $\left(F_{(1,17)}=39.01, p<0.0001\right)$, but not an interaction effect $\left(F_{(1,17)}=0.32, p=0.58\right)$.

Behavioral data (Fig. $3 C, D$ ) from the decision phase indicated that there was a successful transfer of knowledge from the learning phase to the recombined face-scene pairs. Examining the proportion of approach responses (Fig. $3 \mathrm{C}$ ), there was a significant factor of condition $\left(F_{(1.16,19.97)}=149.93, p<0.0001\right)$, with all three conditions being significantly different to each other (all $t_{(53)} \geq 17.68, p<$ $0.0001)$. There was, however, no significant factor of run $\left(F_{(2,34)}=\right.$ $0.13, p=0.88)$ or a significant condition by run interaction $\left(F_{(4,68)}=\right.$ $1.00, p=0.42$ ), suggesting that participants responded similarly across the three fMRI scanning runs. Consistent with the learning data, which suggested better learning of the negative valence images, participants made a greater proportion of avoid responses to the no-conflict negative images compared to approach responses to the no-conflict positive images $\left(t_{(17)}=3.94, p=0.001\right)$. Moreover, participants made a larger proportion of avoid responses $(\sim 0.62)$ compared to approach responses $(\sim 0.38)$ during the conflict trials $\left(t_{(17)}=4.78, p<0.0001\right)$. This bias toward avoidance could reflect better learning of the negative compared to positive valence images and/or participants taking a more conservative approach to conflict trials to avoid the loss of points. Although these factors are difficult to disentangle completely, there is tentative evidence to suggest that both contributed to the pattern of responding for mixed valence image pairs. We calculated a measure of avoidance bias for noconflict trials (proportion avoid for no-conflict negative trials minus proportion approach for no-conflict positive trials) and conflict trials (proportion avoid minus proportion approach for conflict mixed trials). Assuming that response bias on no-conflict trials primarily 
captures better learning of negative compared to positive valence images, we predicted that greater avoidance bias for no-conflict trials would be associated with greater avoidance bias for conflict trials. A bivariate Pearson correlation analysis revealed this relationship $(r=77, p<0.0001$; Fig. 4A), consistent with superior learning of negative valence contributing to conflict trial responding. Overall, however, conflict avoidance bias was significantly greater than no-conflict avoidance bias $\left(t_{(17)}=2.23, p=\right.$ 0.040 ; Fig. $4 B$ ). This suggests that the greater proportion of avoid responses for conflict trials cannot be explained entirely by a learning difference between negative and positive valence images, as participants also took a more measured approach to mixed valence image pairs. Findings from analyses of mean response times were in keeping with this idea, with participants being slower at responding during the conflict trials (Fig. 3D). There was a significant effect of condition $\left(F_{(2.03,34.33)}=8.97, p=0.001\right)$ and $\operatorname{run}\left(F_{(1.41,23.91)}=1.79, p=0.005\right)$, but no significant interaction between these two factors $\left(F_{(6,102)}=1.25, p=0.29\right)$. Exploring the effect of condition further (corrected $p=0.05 / 6=0.0083$ ), there was a significant difference between no-conflict negative avoid and for approached or avoided conflict trials (both $t_{(47)} \geq 4.80, p<0.0001$ ), as well as between no-conflict positive approach and conflict mixed approach $\left(t_{(47)}=\right.$ $5.58, p<0.0001)$. There was a trend towards a significant difference between no-conflict positive approach and conflict mixed avoid $\left(t_{(47)}=2.67, p=0.010\right)$, as well as conflict mixed approach and conflict mixed avoid $\left(t_{(47)}=2.14, p=0.034\right)$, with no significant difference between the two no-conflict trial types $\left(t_{(47)}=0.64, p=0.52\right)$. The effect of run reflected a decrease in response times across fMRI runs, with a significant difference between runs 1 and 2 $\left(t_{(71)}=3.90, p<0.0001\right)$ and 1 and $3\left(t_{(71)}=5.41, p<0.0001\right)$, but not 2 and $3\left(t_{(71)}=1.58, p=0.12\right)$.

Finally, given that each mixed pair was comprised of a face and scene image, we examined whether stimulus category had an impact on responding during conflict trials. Participants responded according to the incentive value of the scene image on $53.24 \%$ (SD, 14.89) of mixed valence trials, thus basing their response on the incentive value of the face image on the remainder $(46.76 \%)$ of these trials. Notably, however, there was no significant difference between these two $\left(t_{(17)}=0.55\right.$, $p=0.59$ ), suggesting that responding on high-conflict trials was not driven primarily by a single stimulus category.

\section{Neuroimaging findings}

Our data-driven PLS analyses revealed two significant LVs that accounted for a total of $70.46 \%$ of the covariance between the design and data matrices. Crucially, significant HC activity was identified in both LVs.
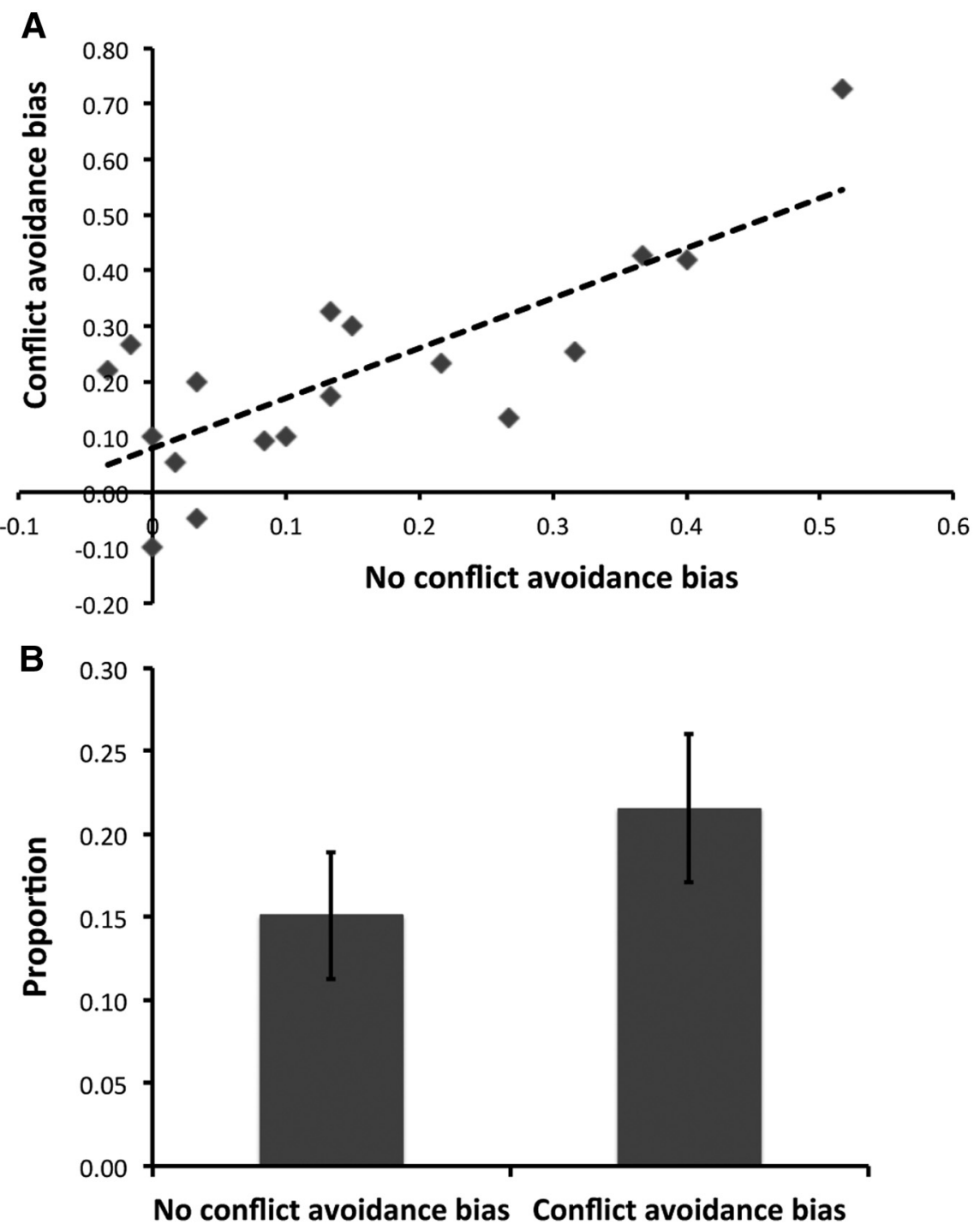

Figure 4. $A$, Significant relationship $(r=0.77, p<0.0001)$ between no-conflict avoidance bias (proportion of avoid responses no-conflict negative trials minus proportion of approach responses on no-conflict positive trials) and conflict avoidance bias (proportion of avoid responses minus proportion of approach responses on conflict mixed trials). $\boldsymbol{B}$, Significant difference between mean no-conflict avoidance bias and conflict avoidance bias $\left(t_{(17)}=2.23, p=0.040\right)$. Error bars indicate SE.

\section{LV1: effect of conflict ( $42.54 \%$ covariance; $\mathrm{p}<0.0001)$}

Inspection of the linear contrast associated with the first LV indicated a reliable distinction between conflict and no-conflict conditions (Fig. 5A). There was a significant difference between the conflict trial types (conflict mixed avoid and conflict mixed approach) and the no-conflict trial types (no-conflict positive approach and no-conflict negative avoid) as well as the baseline condition. Importantly, this LV did not differentiate between conflict mixed avoid and conflict mixed approach trials, nor did it differentiate between any of the no-conflict or baseline trials.

Focusing on our a priori structure of interest, the singular image revealed greater bilateral activity in the posterior portion of the anterior HC during conflict trials compared to no-conflict trials (left, $[-18,-18,-18]$; BSR, 3.91; $p=0.0001 ; 134$ voxels; right, $[20,-22,-20]$; BSR, 3.23; $p=0.001 ; 26$ voxels; TR2; Fig. $5 B)$. This difference was greatest early on in the $15 \mathrm{~s}$ time window that was examined for each trial and was significant during TR2 and TR4 from stimulus onset.

Although we were primarily interested in the $\mathrm{HC}$, we also identified regions in the rest of the brain that were part of the 


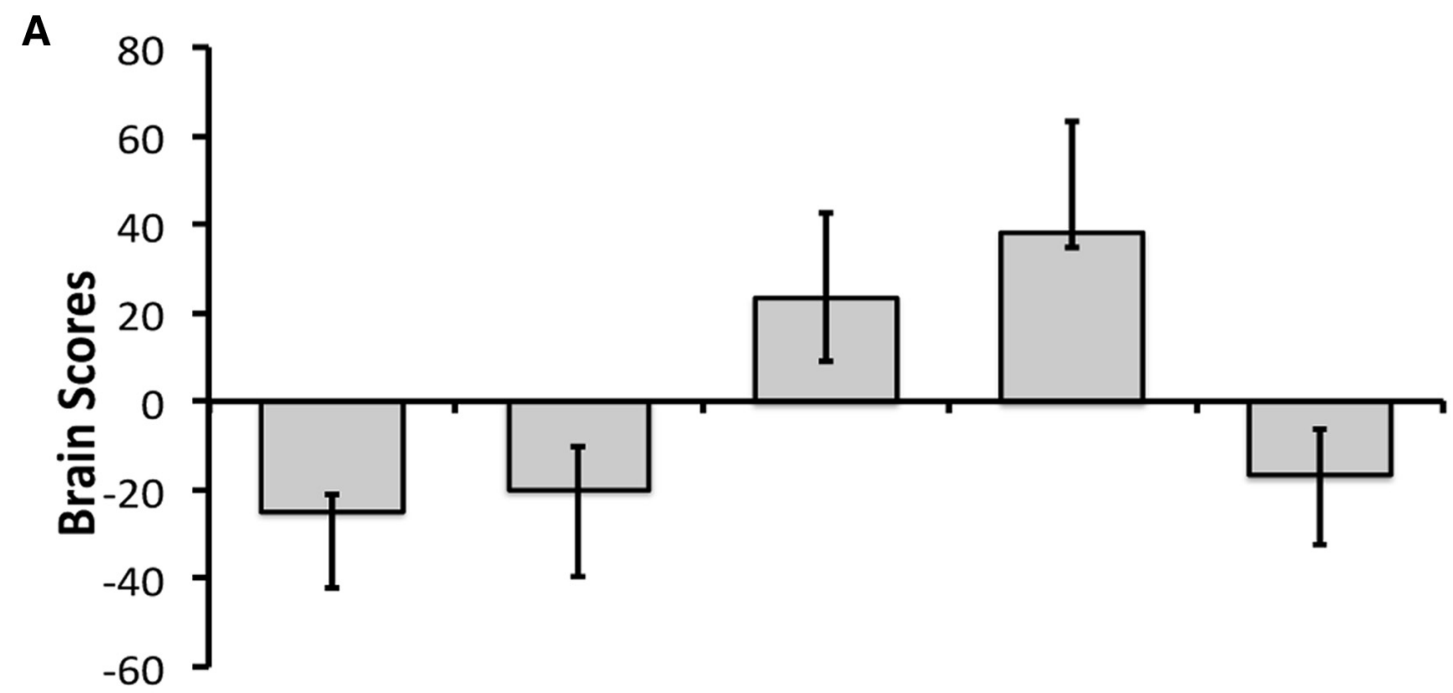

\begin{tabular}{|c|c|c|c|}
\hline No Conflict & No Conflict & Conflict Mixed Conflict Mixed & Scrambled \\
\hline Negative Avoid & $\begin{array}{l}\text { Positive } \\
\text { Approach }\end{array}$ & Approach & Baseline \\
\hline
\end{tabular}

B
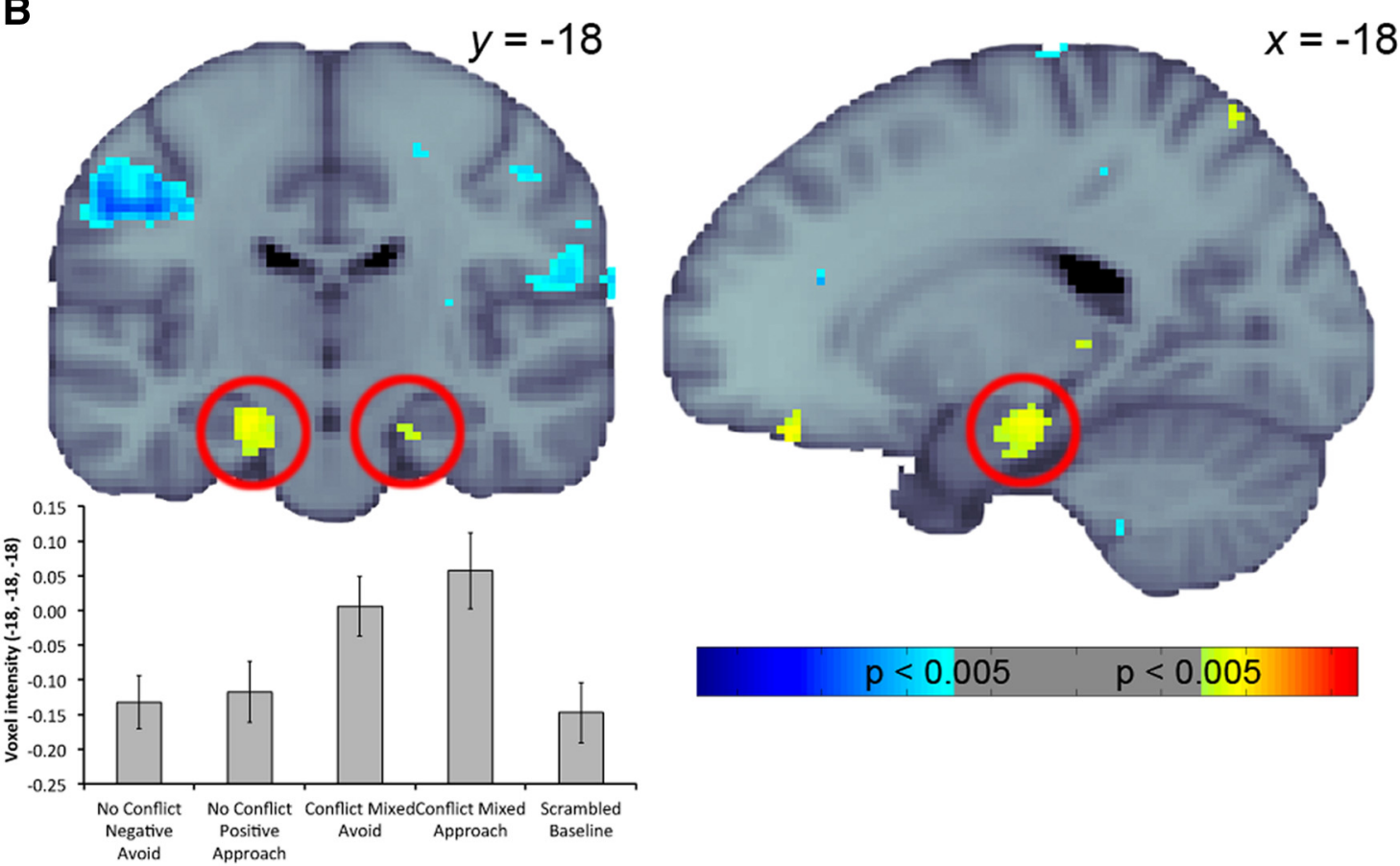

Figure 5. A, Linear contrast associated with the latent variable differentiating conflict conditions from the no-conflict and scrambled baseline conditions. Error bars indicate $95 \%$ Cls. $\boldsymbol{B}$, Pattern of activity relating to $A$ at TR2, with hippocampal activity highlighted with the red circles. Warm colors indicate greater activity during conflict trials compared to no-conflict and scrambled baseline trials, whereas cool colors indicate the opposite. Activity was thresholded at a bootstrap ratio of 2.81 (equivalent to $p=0.005$ ) and rendered on the MNI-152 standard template (the left hemisphere on the coronal slice is the left side of the image). The voxel intensities ( \pm SE) across conditions for the hippocampal voxel contributing most robustly to this pattern are also presented for display purposes.

pattern differentiating conflict trials from no-conflict trials. Beyond the HC, regions more active during conflict trials included a number of areas that have been previously implicated in valence processing and/or decision making, including the posterior cingulate gyrus, paracingulate gyrus, frontal pole, orbitofrontal cortex, anterior cingulate cortex, amygdala, putamen, and caudate. (We provide details of theoretically relevant regions in Table 1 to allow comparison with past findings.)
LV2: effect of response type $(27.92 \%$ covariance; $\mathrm{p}<0.022)$

The LV2 linear contrast revealed a significant difference between approach and avoidance responses within conflict trials and also within no-conflict trials (Fig. 6A). Thus, this LV identified a distinction between approach and avoidance behavior regardless of the degree of conflict involved. There was a cluster of significantly greater activity in the left anterior hippocampus bordering the amygdala ([-24, $-6,-24]$; BSR, $4.66 ; p<0.0001 ; 48$ voxels) 
Table 1. Theoretically relevant regions of activity beyond the hippocampus associated with latent variable 1

\begin{tabular}{|c|c|c|c|c|c|c|c|}
\hline \multirow[b]{2}{*}{ Region } & \multirow[b]{2}{*}{ Hemisphere } & \multicolumn{3}{|c|}{ MNI coordinates } & \multirow{2}{*}{$\begin{array}{l}\text { Bootstrap } \\
\text { ratio }\end{array}$} & \multirow{2}{*}{$\begin{array}{l}\text { Approximate } \\
p \text { value }\end{array}$} & \multirow{2}{*}{$\begin{array}{l}\text { Cluste } \\
\text { size }\end{array}$} \\
\hline & & $x$ & $y$ & $z$ & & & \\
\hline \multicolumn{8}{|l|}{ TR2 } \\
\hline $\begin{array}{l}\text { Posterior cingulate } \\
\text { gyrus }\end{array}$ & $\mathrm{L}$ & -4 & -42 & 4 & 5.40 & $<0.0001$ & 749 \\
\hline Paracingulate gyrus & $\mathrm{L}$ & -8 & 10 & 50 & 4.78 & $<0.0001$ & 388 \\
\hline Frontal pole & L & -32 & 34 & -10 & 4.67 & $<0.0001$ & 162 \\
\hline Amygdala & L & -24 & 4 & -24 & 3.79 & 0.0001 & 23 \\
\hline \multicolumn{8}{|l|}{ TR3 } \\
\hline Orbitofrontal cortex & L & -44 & 18 & -10 & 5.68 & $<0.0001$ & 376 \\
\hline $\begin{array}{l}\text { Posterior cingulate } \\
\text { gyrus }\end{array}$ & B & 0 & -38 & 4 & 5.31 & $<0.0001$ & 479 \\
\hline Frontal pole & $\mathrm{R}$ & 2 & 50 & 48 & 4.48 & $<0.0001$ & 228 \\
\hline Orbitofrontal cortex & $\mathrm{R}$ & 44 & 22 & -6 & 3.41 & 0.0009 & 46 \\
\hline \multicolumn{8}{|l|}{ TR4 } \\
\hline $\begin{array}{l}\text { Posterior cingulate } \\
\text { gyrus }\end{array}$ & $\mathrm{L}$ & -2 & -36 & 16 & 5.04 & 0.0001 & 254 \\
\hline Putamen & $\mathrm{R}$ & 18 & 6 & -2 & 4.88 & 0.0001 & 179 \\
\hline Putamen & L & -28 & -4 & -2 & 4.55 & 0.0001 & 315 \\
\hline Paracingulate gyrus & B & 0 & 28 & 36 & 4.33 & 0.0001 & 733 \\
\hline Orbitofrontal cortex & L & -40 & 30 & -10 & 4.15 & 0.0001 & 606 \\
\hline Orbitofrontal cortex & $\mathrm{R}$ & 30 & 16 & -28 & 4.15 & 0.0001 & 269 \\
\hline Frontal pole & $\mathrm{R}$ & 20 & 44 & 40 & 3.76 & 0.0002 & 87 \\
\hline Caudate & L & -12 & 6 & 10 & 3.59 & 0.0003 & 32 \\
\hline \multicolumn{8}{|l|}{ TR5 } \\
\hline Frontal pole & $\mathrm{R}$ & 18 & 36 & -20 & 6.29 & $<0.0001$ & 95 \\
\hline $\begin{array}{l}\text { Anterior cingulate } \\
\text { gyrus }\end{array}$ & L & -12 & 32 & 16 & 6.13 & $<0.0001$ & 290 \\
\hline Amygdala & $\mathrm{R}$ & 18 & 0 & -22 & 4.30 & $<0.0001$ & 34 \\
\hline Caudate & $\mathrm{R}$ & 14 & 18 & 4 & 3.20 & 0.001 & 16 \\
\hline
\end{tabular}

$L$, Left; $R$, right; B, bilateral.

associated with approach responses compared to avoidance responses, and this activity was significant during TR2 only (Fig. 6B). Beyond this, a number of regions were also associated with significantly greater activity during approach responses, including the parahippocampal cortex, paracingulate gyrus, temporal fusiform cortex, orbitofrontal cortex, insular cortex, thalamus, frontal pole, temporal occipital fusiform cortex, inferior temporal gyrus, and entorhinal cortex. (We provide details of theoretically relevant regions in Table 2 to allow comparison with past findings.)

\section{MVPA results}

Finally, targeted assessment of anterior and posterior aspects of the HC using MVPA also indicated anterior $\mathrm{HC}$ sensitivity to our experimental manipulation. Using bilateral anterior and posterior HC masks of equal voxel number (see Materials and Methods), we compared three-way classification performance for positive, negative, and mixed valence pairings using one-way $t$ tests against chance $(33.33 \%)$. This analysis revealed significant classification performance in the anterior HC $\left(36.61 \% ; t_{(1,17)}=\right.$ $3.944, p=0.001)$, but not the posterior HC $\left(34.17 \% ; t_{(1,17)}=\right.$ $0.811, p=0.43)$. Direct comparison of three-way classification performance in anterior and posterior regions revealed marginally greater classification performance in the anterior ROI $\left(t_{(1,17)}=2.06, p=0.055\right)$. To explore this finding further, we directly compared classification performance for no-conflict and conflict conditions. Two-way classification performance was calculated for positive versus mixed and negative versus mixed conditions, and then averaged for each participant. Classification performance was significantly above chance $(50 \%)$ in the anterior $\mathrm{HC}$ mask $\left(53.47 \% ; t_{(1,17)}=5.12, p<0.001\right)$. Unlike the three-way classification findings, however, classification perfor- mance in the posterior $\mathrm{HC}$ mask was also significantly better than chance $\left(51.94 \% ; t_{(1,17)}=2.21, p=0.041\right)$. Critically, a direct comparison of anterior and posterior ROIs revealed significantly greater classification performance in anterior $\mathrm{HC}\left(t_{(1,17)}=2.13\right.$, $p=0.048)$. Together, the MVPA findings point toward greater anterior HC sensitivity to our conflict manipulation and, consistent with the findings of the PLS analyses as well as previous work in rodents and humans, are suggestive of a privileged role of the anterior HC in approach-avoidance conflict processing. [Note that a traditional univariate statistical approach to the neuroimaging data also yielded similar HC findings: the contrast (conflict mixed valence approach + conflict mixed valence avoid) - (noconflict positive valence approach + no-conflict negative valence avoid) revealed a significant cluster of activity in the right anterior HC (maxima [26, $-16,22]$; 15 voxels; $p=0.013$, small volume corrected using the bilateral Harvard-Oxford subcortical HC mask thresholded at 50\%).]

\section{Discussion}

Using a unique experimental task in conjunction with multivariate fMRI, we have revealed differential recruitment of the human anterior $\mathrm{HC}$ when behavioral decisions are made under conditions with, as compared to without, approach-avoidance conflict. Notably, since our paradigm was designed to control for spatial and mnemonic processing, we provide important evidence beyond previous work in humans and rodents that examined HC approach-avoidance conflict in the context of varying spatial/foraging and/or memory demands (Bach et al., 2014; Bannerman et al., 2014). Furthermore, by examining neural activity during both approach and avoidance responses to stimuli for which the incentive values were learned, the current study provides, to our knowledge, one of the first insights into human HC involvement during adaptive approach and avoidance decision making.

A key strength of the current study was the success of our behavioral task in eliciting the presence or absence of approachavoidance conflict in participants. Despite no explicit warning that image pairs presented during the learning phase of the study would be later recombined, and the absence of feedback during the decision phase, approach-avoidance responses of participants to recombined pairings reflected knowledge of stimulus valence. Participants were strongly biased toward approaching no-conflict positive pairs and avoiding no-conflict negative pairs. In contrast, participants responded in a haphazard manner to image pairs constructed from images of conflicting valence and took significantly longer to make a response for these mixed valence pairings, as would be expected under conditions of approach-avoidance conflict.

Crucially, perceptual and mnemonic demands were matched across all experimental conditions. Every trial at test consisted of a novel recombination of a previously viewed scene and face, and the left/right locations of the face and scene images within each pair were counterbalanced. In addition to this, all face-scene pairs during the decision phase necessitated the retrieval of two separately acquired incentive values regardless of conflict level, corresponding to the reward/punishment contingencies of the originally studied face-scene pairs. Thus, any increases in activity observed during conflict, compared to no-conflict, trials cannot be attributed to any differences in spatial or mnemonic processing demands between these two levels of conflict. Actively controlling for spatial and mnemonic demands is important since approach-avoidance conflict can impact hippocampally dependent spatial and memory processes. For instance, exposure to reward and punishment in the context of paradigms that rely on 
A

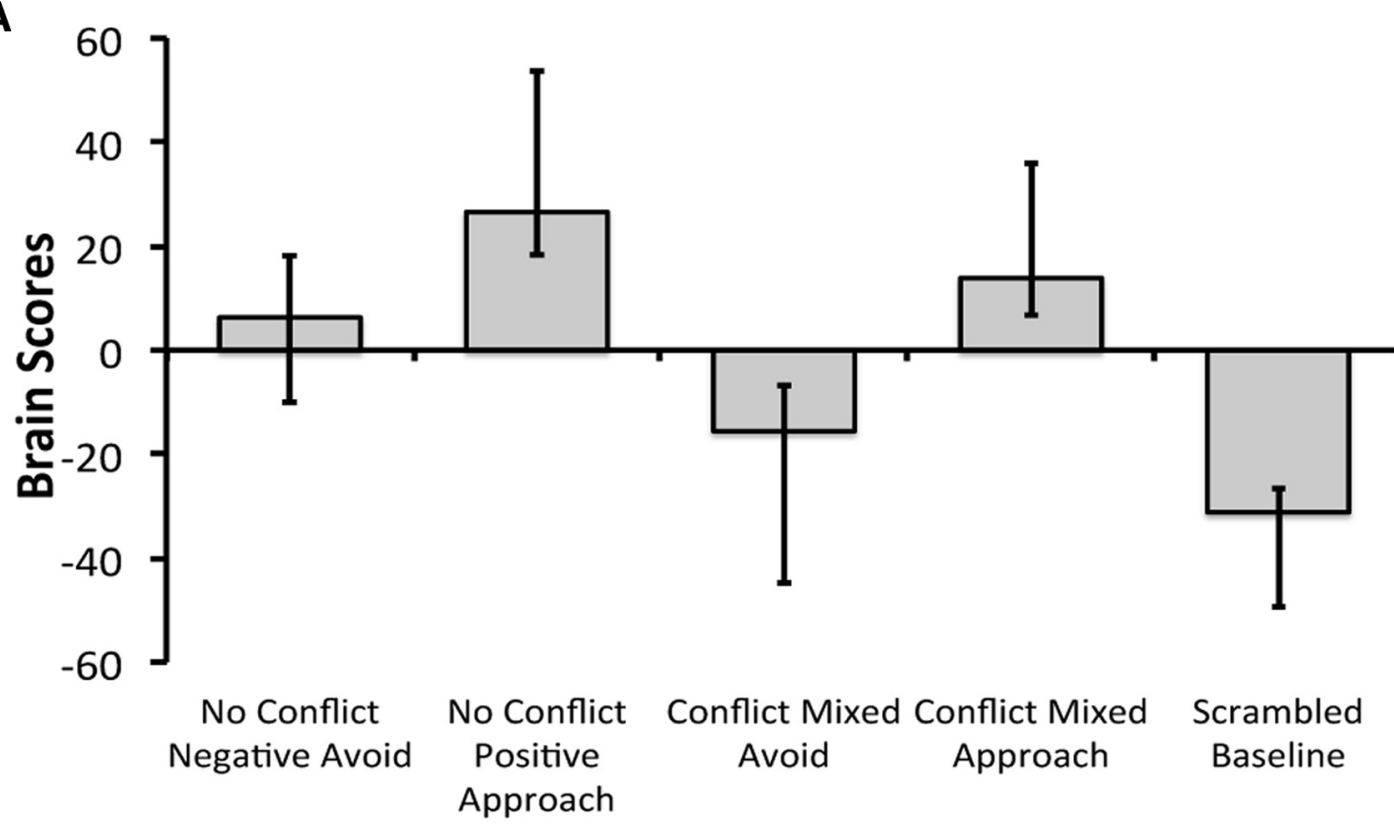

B
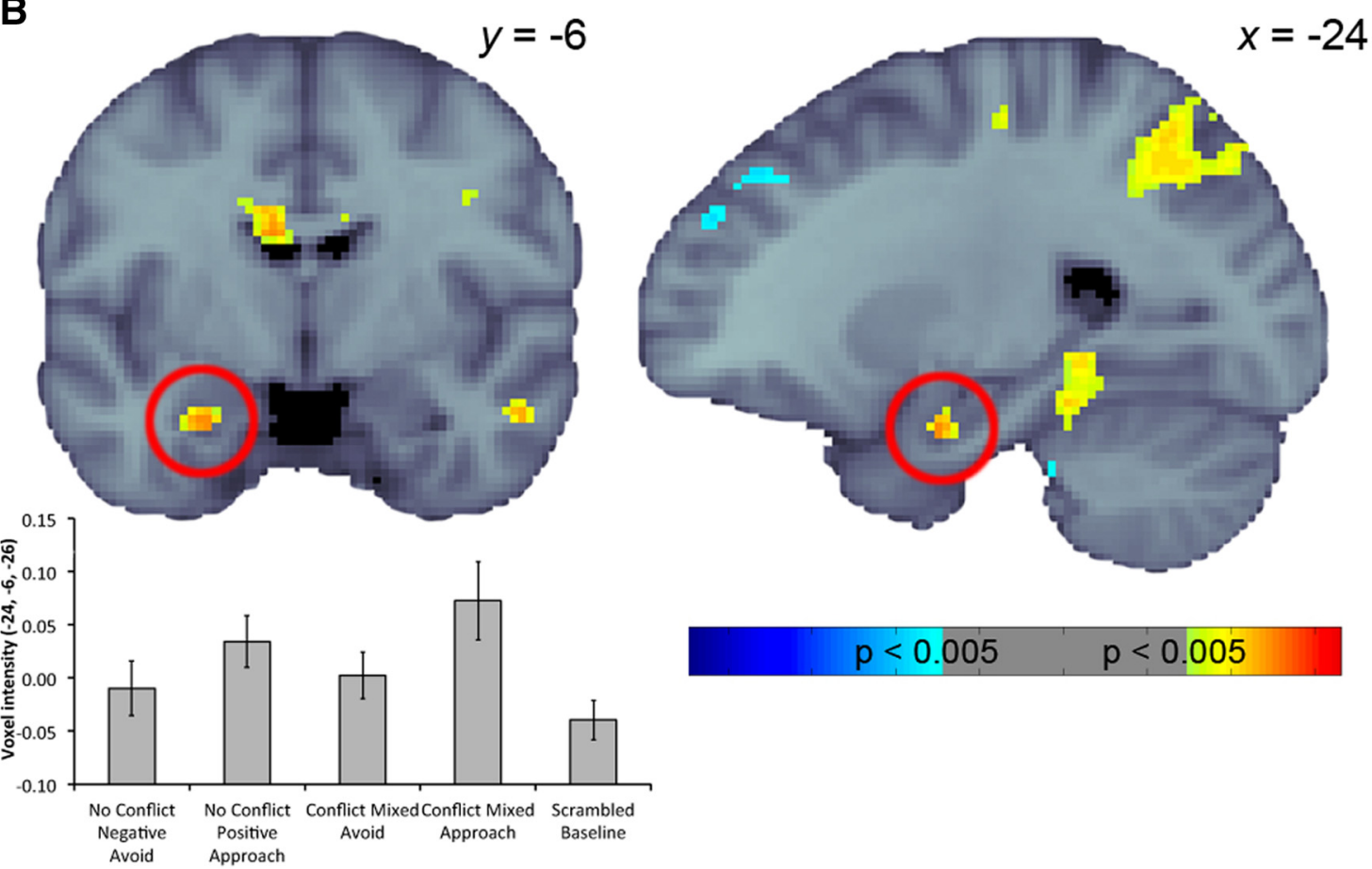

$p<0.005$

$p<0.005$

Figure 6. A, Linear contrast associated with the latent variable differentiating approach from avoid responses for no-conflict and conflict trials. Error bars indicate $95 \%$ Cls. $B$, Pattern of activity relating to $A$ at TR2, with hippocampal activity highlighted with the red circles. Warm colors indicate greater activity during conflict trials compared to no-conflict and scrambled baseline trials, whereas cool colors indicate the opposite. Activity was thresholded at a bootstrap ratio of 2.81 (equivalent to $p=0.005$ ) and rendered on the MNI-152 standard template (the left hemisphere on the coronal slice is the left side of the image). The voxel intensities ( \pm SE) across conditions for the hippocampal voxel contributing most robustly to this pattern are also presented for display purposes.

subject locomotion inevitably shape both the extent and quality of spatial exploration. Furthermore, in a task in which participants are required to learn the probability of a threat appearing (Bach et al., 2014), high-conflict contexts are inherently associated with a greater number of aversive experiences (leading to a high probability of threat) compared to low-conflict contexts (i.e., low probability of threat). These differences in spatial and/or mnemonic processing may result in differences in HC involve- ment between conditions of varying conflict levels, unrelated to the process of approach-avoidance conflict decision making.

A critical feature of the present behavioral paradigm is that high conflict was created by simultaneously presenting an aversive stimulus and a rewarding stimulus, both of which were learned by the participants before the decision-making phase. Much existing work on conflict decision making has focused on unlearned behavior, such as the desire of an animal to explore a 
Table 2. Theoretically relevant regions of activity beyond the hippocampus associated with latent variable 2

\begin{tabular}{|c|c|c|c|c|c|c|c|}
\hline \multirow[b]{2}{*}{ Region } & \multirow[b]{2}{*}{ Hemisphere } & \multicolumn{3}{|c|}{ MNI coordinates } & \multirow{2}{*}{$\begin{array}{l}\text { Bootstrap } \\
\text { ratio }\end{array}$} & \multirow{2}{*}{$\begin{array}{l}\text { Approximate } \\
p \text { value }\end{array}$} & \multirow{2}{*}{$\begin{array}{l}\text { Cluster } \\
\text { size }\end{array}$} \\
\hline & & $x$ & $y$ & $z$ & & & \\
\hline \multicolumn{8}{|l|}{ TR2 } \\
\hline $\begin{array}{l}\text { Parahippocampal } \\
\text { cortex }\end{array}$ & L & -18 & -38 & -14 & 6.29 & $<0.0001$ & 547 \\
\hline Paracingulate gyrus & $\mathrm{R}$ & 6 & 12 & 50 & 6.15 & $<0.0001$ & 956 \\
\hline $\begin{array}{l}\text { Temporal fusiform } \\
\text { cortex }\end{array}$ & $\mathrm{R}$ & 34 & -36 & -22 & 5.04 & $<0.0001$ & 1085 \\
\hline Orbitofrontal cortex & L & -34 & 26 & -4 & 4.07 & $<0.0001$ & 31 \\
\hline Insular cortex & $\mathrm{R}$ & 36 & 22 & -4 & 3.90 & 0.0001 & 75 \\
\hline Thalamus & $\mathrm{R}$ & 6 & -12 & 2 & 3.78 & 0.0002 & 24 \\
\hline Frontal pole & L & -46 & 50 & -10 & 3.70 & 0.0002 & 41 \\
\hline \multicolumn{8}{|l|}{ TR3 } \\
\hline $\begin{array}{l}\text { Temporal occipital } \\
\text { fusiform cortex }\end{array}$ & R & 38 & -44 & -24 & 5.17 & 0.0001 & 1486 \\
\hline $\begin{array}{l}\text { Inferior temporal } \\
\text { gyrus }\end{array}$ & L & -46 & -48 & -26 & 5.17 & 0.0001 & 839 \\
\hline $\begin{array}{l}\text { Parahippocampal } \\
\text { cortex }\end{array}$ & L & -16 & -42 & -16 & 3.47 & 0.0005 & 27 \\
\hline \multicolumn{8}{|l|}{ TR5 } \\
\hline Entorhinal cortex & $\mathrm{R}$ & 10 & -6 & -24 & 4.11 & 0.0001 & 10 \\
\hline
\end{tabular}

potentially dangerous environment for food reward (Bannerman et al., 2014), or the fear of a predator or physically unpleasant stimulus (Geller and Seifter, 1960; Blanchard and Blanchard, 1990; Millan, 2003). Although approach-avoidance conflict arising from such stimuli offer insight into the neural mechanisms underlying conflict processing, they do not capture the full range of scenarios in which approach-avoidance conflict can occur. Previously neutral stimuli can acquire incentive values over time and these incentive values can conflict in real-world situations, for instance, spotting an unpleasant ex-colleague sitting adjacent to your reserved table at a favorite restaurant. Our study, therefore, builds on previous research by demonstrating a role for the $\mathrm{HC}$ in conflict decision making for stimuli that lack innate incentive values, an important extension given that many sources of conflict-induced anxiety are not innately known.

Our data-driven PLS analysis revealed that the LV accounting for the highest proportion of covariance between the data and task matrices reflected a significant difference between conflict trials and no-conflict/baseline trials, a distinction that was further confirmed using a multivariate classifier approach. This was associated with a significant increase in $\mathrm{HC}$ activity for both approach and avoidance responses to conflict image pairs, although interestingly, there was no significant difference between these two (Fig. 5A). Approaching a potentially threatening stimulus or context has been linked to increased anxiety (McNaughton and Corr, 2004), and in rodents, considerable work has highlighted a role for the ventral HC in anxiety. For instance, rats with ventral HC lesions are more likely to approach a potentially dangerous environment such as an open elevated maze arm (Bannerman et al., 2002, 2003; Kjelstrup et al., 2002; Trivedi and Coover, 2004), and furthermore, ventral HC damage has been shown to attenuate defensive behavior in the presence of a threat (Pentkowski et al., 2006). According to this viewpoint, HC activity increase during approach responses could reflect greater anxiety associated with approaching a stimulus pair for which there is the potential for punishment (i.e., point loss). Consistent with this, there was a trend for conflict approach response times to be significantly longer than those for conflict avoidance responses $(p=0.034$; corrected $p$ value threshold, $p=0.0083$ ). Critically, however, it is difficult to see how increased anxiety can account for elevated HC activity during conflict avoidance trials, as participants chose the safe option by avoiding a potential point deduction. Indeed, avoiding a potentially threatening stimulus/context has been proposed to be associated with fear rather than anxiety (McNaughton and Corr, 2004). Instead, we suggest that the observed $\mathrm{HC}$ activity during conflict approach and avoid trials may reflect the processing of conflicting learned valence information and/or the regulation of approach/avoidance behavior. Although our current behavioral paradigm is unable to pinpoint the exact processes contributing to this activity, potential processes include the detection and resolution of conflict and execution of appropriate behavior. Interestingly, the current observation of $\mathrm{HC}$ activity during both conflict approach and avoidance responses is not inconsistent with the theory that the HC may play a key role in controlling defensive behavior (Gray and McNaughton, 2000; McNaughton and Corr, 2004). According to this viewpoint, the $\mathrm{HC}$ may not only regulate avoidance in response to perceived danger, but also exploratory behavior for risk assessment when there is uncertainty of reward or punishment.

The second LV from our PLS analysis identified an anterior aspect of $\mathrm{HC}$ extending into the amygdala as part of a larger pattern of activity that distinguished approach and avoid responses during no-conflict as well as conflict trials. Inspection of the linear contrast associated with this LV revealed that noconflict approach and conflict approach trials contributed similarly to this distinction, suggesting that the observed anterior $\mathrm{HC}$ /amygdala effect in LV2 is not related to risk or uncertainty. It was suggested previously that a number of regions including the amygdala and orbitofrontal cortex (both of which were part of the pattern expressed in LV2) are critical for adapting to changes in stimulus-reward relationships (Cools et al., 2004; Kesner and Rogers, 2004; Goto and Grace, 2005; Kringelbach, 2005). Related to this, one possibility is that the anterior hippocampal/amygdala involvement present in the second LV reflects the fact that during the learning phase, approach, but not avoid, responses were associated with active reward or punishment and therefore impacted the amount of game points accrued. We speculate that although feedback was not present during the decision phase, differential recruitment of this network in association with approach decisions to recombined image pairs may reflect facilitation or priming of monitoring/updating processes previously recruited during learning for approach responses.

Finally, although our focus was on the HC, it is important to acknowledge that a number of other areas were part of the pattern of regions preferentially active during conflict approach and avoidance behavior (LV1). These included the paracingulate cortex, posterior cingulate gyrus, anterior cingulate cortex, orbitofrontal cortex, frontopolar cortex, caudate, and amygdala. Although a full discussion of these regions is beyond the scope of the current paper, these regions have been associated previously with conflict resolution, incentive-value learning, and/or decision making (for review, see Krain et al., 2006; Rushworth et al., 2011). For example, the posterior cingulate gyrus has been implicated in encoding reward values and probabilities, which may be particularly important during decision making under conditions of high conflict (McCoy et al., 2003; Pearson et al., 2011). The anterior cingulate cortex has been suggested to be involved in conflict monitoring (Botvinick et al., 2004) and detection (Oehrn et al., 2014), and processing positive and negative feedback to guide behavior (Quilodran et al., 2008). In addition, the anterior prefrontal cortex has been suggested to maintain representations of nonchosen stimuli/outcomes to guide future decision making 
(Koechlin et al., 1999; Koechlin and Hyafil, 2007), whereas lateral orbitofrontal cortex as well as the amygdala have been demonstrated to be sensitive to ambiguity in choice (Hsu et al., 2005).

In summary, existing rodent work has highlighted a role of the ventral HC in conflict processing in approach/avoidance paradigms (Bannerman et al., 2014). Here, using a novel task designed to control spatial/mnemonic processing and use learned valence, we demonstrated that the anterior HC, the human homolog of this region, is similarly sensitive to conflict. Our findings suggest that the anterior HC may be a key part of a larger network of cortical and subcortical regions, which is important for shaping adaptive behavior under conditions of uncertainty.

\section{References}

Abela AR, Dougherty SD, Fagen ED, Hill CJ, Chudasama Y (2013) Inhibitory control deficits in rats with ventral hippocampal lesions. Cereb Cortex 23:1396-1409. CrossRef Medline

Adhikari A, Topiwala MA, Gordon JA (2010) Synchronized activity between the ventral hippocampus and the medial prefrontal cortex during anxiety. Neuron 65:257-269. CrossRef Medline

Adhikari A, Topiwala MA, Gordon JA (2011) Single units in the medial prefrontal cortex with anxiety-related firing patterns are preferentially influenced by ventral hippocampal activity. Neuron 71:898-910. CrossRef Medline

Aggleton JP (2012) Multiple anatomical systems embedded within the primate medial temporal lobe: implications for hippocampal function. Neurosci Biobehav Rev 36:1579-1596. CrossRef Medline

Bach DR, Guitart-Masip M, Packard PA, Miró J, Falip M, Fuentemilla L, Dolan RJ (2014) Human hippocampus arbitrates approach-avoidance conflict. Curr Biol 24:541-547. CrossRef Medline

Bannerman DM, Deacon RM, Offen S, Friswell J, Grubb M, Rawlins JN (2002) Double dissociation of function within the hippocampus: Spatial memory and hyponeophagia. Behav Neurosci 116:884-901. CrossRef Medline

Bannerman DM, Grubb M, Deacon RM, Yee BK, Feldon J, Rawlins JN (2003) Ventral hippocampal lesions affect anxiety but not spatial learning. Behav Brain Res 139:197-213. CrossRef Medline

Bannerman DM, Sprengel R, Sanderson DJ, McHugh SB, Rawlins JN, Monyer H, Seeburg PH (2014) Hippocampal synaptic plasticity, spatial memory and anxiety. Nat Rev Neurosci 15:181-192. CrossRef Medline

Blanchard RJ, Blanchard DC (1990) An ethoexperimental analysis of defense, fear and anxiety. In: Anxiety (McNaughton N, Andrews G, eds), pp 124-133. Dunedin, New Zealand: Otago UP.

Botvinick MM, Cohen JD, Carter CS (2004) Conflict monitoring and anterior cingulate cortex: an update. Trends Cogn Sci 8:539-546. CrossRef Medline

Cools R, Clark L, Robbins TW (2004) Differential responses in human striatum and prefrontal cortex to changes in object and rule relevance. J Neurosci 24:1129-1135. CrossRef Medline

Geller I, Seifter J (1960) The effects of meprobamate, barbiturates, $\mathrm{d}$-amphetamine and promazine on experimentally induced conflict in the rat. Psychopharmacologia 1:482-492. CrossRef

Glover GH (2012) Spiral imaging in fMRI. Neuroimage, 62:706-712. CrossRef

Goto Y, Grace AA (2005) Dopamine-dependent interactions between limbic and prefrontal cortical plasticity in the nucleus accumbens: disruption by cocaine sensitization. Neuron 47:255-266. CrossRef Medline

Gray JA, McNaughton N (2000) The neuropsychology of anxiety, Ed 2. Oxford, UK: Oxford UP.

Hsu M, Bhatt M, Adolphs R, Tranel D, Camerer CF (2005) Neural systems responding to degrees of uncertainty in human decision-making. Science 310:1680-1683. CrossRef Medline

Johnson A, van der Meer MA, Redish AD (2007) Integrating hippocampus and striatum in decision-making. Curr Opin Neurobiol 17:692-697. CrossRef Medline

Kesner RP, Rogers J (2004) An analysis of independence and interactions of brain substrates that subserve multiple attributes, memory systems, and underlying processes. Neurobiol Learn Mem 82:199-215. CrossRef Medline

Kjelstrup KG, Tuvnes FA, Steffenach HA, Murison R, Moser EI, Moser MB (2002) Reduced fear expression after lesions of the ventral hippocampus. Proc Natl Acad Sci U S A 99:10825-10830. CrossRef Medline

Koechlin E, Hyafil A (2007) Anterior prefrontal function and the limits of human decision-making. Science 318:594-598. CrossRef Medline

Koechlin E, Basso G, Pietrini P, Panzer S, Grafman J (1999) The role of the anterior prefrontal cortex in human cognition. Nature 399:148-151. CrossRef Medline

Konkle T, Brady TF, Alvarez GA, Oliva A (2010) Scene memory is more detailed than you think: the role of categories in visual long-term memory. Psychol Sci 21:1551-1556. CrossRef Medline

Krain AL, Wilson AM, Arbuckle R, Castellanos FX, Milham MP (2006) Distinct neural mechanisms of risk and ambiguity: a meta-analysis of decision-making. Neuroimage 32:477-484. CrossRef Medline

Kringelbach ML (2005) The human orbitofrontal cortex: linking reward to hedonic experience. Nat Rev Neurosci 6:691-702. CrossRef Medline

Krishnan A, Williams LJ, McIntosh AR, Abdi H (2011) Partial Least Squares (PLS) methods for neuroimaging: a tutorial and review. Neuroimage 56: 455-475. CrossRef Medline

Mayes A, Montaldi D, Migo E (2007) Associative memory and the medial temporal lobes. Trends Cogn Sci 11:126-135. CrossRef Medline

McCoy AN, Crowley JC, Haghighian G, Dean HL, Platt ML (2003) Saccade reward signals in posterior cingulate cortex. Neuron 40:1031-1040. CrossRef Medline

McHugh SB, Deacon RM, Rawlins JN, Bannerman DM (2004) Amygdala and ventral hippocampus contribute differentially to mechanisms of fear and anxiety. Behav Neurosci 118:63-78. CrossRef Medline

McIntosh AR, Lobaugh NJ (2004) Partial least squares analysis of neuroimaging data: applications and advances. Neuroimage 23 [Suppl 1]: S250-S263. Medline

McIntosh AR, Chau WK, Protzner AB (2004) Spatiotemporal analysis of event-related fMRI data using partial least squares. Neuroimage 23: 764-775. CrossRef Medline

McNaughton N, Corr PJ (2004) A two-dimensional neuropsychology of defense: fear/anxiety and defensive distance. Neurosci Biobehav Rev 28: 285-305. CrossRef Medline

Millan MJ (2003) The neurobiology and control of anxious states. Prog in Neurobiol 70:83-244. CrossRef

Mumford JA, Turner BO, Ashby FG, Poldrack RA (2012) Deconvolving BOLD activation in event-related designs for multivoxel pattern classification analyses. Neuroimage 59:2636-2643. CrossRef Medline

Nguyen D, Schumacher A, Erb S, Ito R (2015) Aberrant approachavoidance conflict resolution following repeated cocaine pre-exposure. Psychopharmacology 232:3573-3583. CrossRef

Oehrn CR, Hanslmayr S, Fell J, Deuker L, Kremers NA, Do Lam AT, Elger CE, Axmacher N (2014) Neural communication patterns underlying conflict detection, resolution, and adaptation. J Neurosci 34:10438-10452. CrossRef Medline

Oehrn CR, Baumann C, Fell J, Lee H, Kessler H, Habel U, Hanslmayr S, Axmacher N (2015) Human hippocampal dynamics during response conflict. Curr Biol 25:2307-2313. CrossRef Medline

Pearson JM, Heilbronner SR, Barack DL, Hayden BY, Platt ML (2011) Posterior cingulate cortex: Adapting behavior to a changing world. Trends Cogn Sci 15:143-151. CrossRef Medline

Pentkowski NS, Blanchard DC, Lever C, Litvin Y, Blanchard RJ (2006) Effects of lesions to the dorsal and ventral hippocampus on defensive behaviors in rats. Eur J Neurosci 23:2185-2196. CrossRef Medline

Quilodran R, Rothé M, Procyk E (2008) Behavioral shifts and action valuation in the anterior cingulate cortex. Neuron 57:314-325. CrossRef Medline

Righi G, Peissig JJ, Tarr MJ (2012) Recognizing disguised faces. Vis Cogn 20:143-169. CrossRef

Rushworth MF, Noonan MP, Boorman ED, Walton ME, Behrens TE (2011) Frontal cortex and reward-guided learning and decision-making. Neuron 70:1054-1069. CrossRef Medline

Schumacher A, Vlassov E, Ito R (2015) The ventral hippocampus, but not the dorsal hippocampus is critical for learned approach-avoidance decision making. Hippocampus, in press.

Strange BA, Witter MP, Lein ES, Moser EI (2014) Functional organization of the hippocampal longitudinal axis. Nat Neurosci Rev 15:655-669. CrossRef

Trivedi MA, Coover GD (2004) Lesions of the ventral hippocampus, but not the dorsal hippocampus, impair conditioned fear expression and inhibitory avoidance on the elevated T-maze. Neurobiol Learn Mem 81:172184. CrossRef Medline

Vogel JR, Beer B, Clody DE (1971) A simple and reliable conflict procedure for testing anti-anxiety agents. Psychopharmacologia 21:1-7. CrossRef Medline

Wimmer GE, Shohamy D (2012) Preference by association: how memory mechanisms in the hippocampus bias decisions. Science 338:270-273. CrossRef Medline 